\title{
Making Talk Cheap (and Problems Easy): How Legal and Political Institutions Can Facilitate Consensus
}

\author{
Cheryl Boudreau, Mathew D. McCubbins, Daniel B. Rodriguez, and \\ Nicholas Weller*
}

\begin{abstract}
In many legal, political, and social settings, people must reach a consensus before particular outcomes can be achieved and failing to reach a consensus may be costly. In this article, we present a theory and conduct experiments that take into account the costs associated with communicating, as well as the difficulty of the decisions that groups make. We find that when there is even a small cost (relative to the potential benefit) associated with sending information to others and/or listening, groups are much less likely to reach a consensus, primarily because they are less willing to communicate with one another. We also find that difficult problems significantly reduce group members' willingness to communicate with one another and, therefore, hinder their ability to reach a consensus.
\end{abstract}

In many legal, political, and social settings, people must reach a consensus before particular outcomes can be achieved. For example, a conviction in U.S. criminal cases requires jurors to reach a consensus about the guilt of the accused. In the United Nations, the five permanent members of the Security Council must reach a consensus to issue a resolution. In many legislatures, agencies, and lower courts, a consensus (or near consensus) is also necessary when making particular types of decisions. In all these settings, reaching a consensus is important not only because it is required for producing particular outcomes, but also because there are often significant costs associated with failing to reach a consensus. Indeed, a jury that fails to reach a consensus can result in

\footnotetext{
*Address correspondence to Nicholas Weller, University of Southern California, Department of Political Science and School of International Relations, Von KleinSmid Ctr., 327, Los Angeles, CA 90089-0044; email: nweller@usc.edu. Boudreau is Assistant Professor of Political Science at the University of California, Davis; McCubbins is Provost Professor of Business, Law and Political Economy, Marshall School of Business, Gould School of Law, and Department of Political Science at the University of Southern California; Rodriguez is Minerva House Drysdale Regents Chair in Law at the University of Texas at Austin; Weller is Assistant Professor in the Department of Political Science and the School of International Relations at the University of Southern California.

This article was presented at the Conference on Empirical Legal Studies at the University of Southern California, 2009. We are grateful to Paul Zak, Oliver Goodenough, and Matthew Spitzer for helpful comments on an earlier draft of this article.
} 
a mistrial, Supreme Court justices who fail to reach a consensus can produce weak precedent, and legislators who fail to reach a consensus can face substantial political costs at election time. We value consensus because it strengthens the force of the decision reached. We value it, as well, because more consensual decision making coincides with our commitment to democracy as a means of reaching broad agreement on social and political objectives.

Because a consensus is often required to achieve legal and political outcomes and because failing to reach a consensus may be costly, it is important to understand the conditions that facilitate or hinder groups' ability to reach unanimous decisions. Although many scholars seek to identify these conditions by modeling the communication process through which groups reach a consensus, their models typically ignore key features of communication that may affect a group's ability to reach a consensus. Specifically, existing models of consensus typically do not incorporate the fact that there are always costs associated with communicating. That is, both sending information to others and listening require time, energy, and attention that could be spent doing something else (Lupia \& McCubbins 1998). Existing models of consensus also do not typically consider whether and how the nature of the problem (i.e., how difficult or easy it is) affects a group's ability to reach a consensus.

In this article, we build on existing research about consensus by presenting experiments that explicitly take into account the costs associated with communicating, as well as the difficulty of the decisions that groups make. In our experiments, group members have an incentive to reach a consensus about the correct solutions to various problems. Group members may communicate with one another in an attempt to reach a consensus, but we vary the costs associated with sending information to others and listening, as well as the difficulty of the problem.

Consistent with existing research on consensus, we find that when communication is costless, group members can achieve a consensus about the correct solution to a problem. However, when there is even a small cost (relative to the potential benefit) associated with sending information and/or listening, groups are much less likely to reach a consensus, primarily because they are less willing to communicate with one another about the correct solution to the problem. Thus, even though all group members benefit if a consensus is reached, small costs of communication prevent the group from reaching an agreement. We also find that difficult problems significantly reduce group members' willingness to communicate with one another and, therefore, hinder their ability to reach a consensus. Ironically, our experiments suggest that when problems are difficult, and communication is most needed, it will be least likely to occur. Taken together, these results imply that legal and political institutions can facilitate consensus by making communication cheap and problems easy.

This article proceeds as follows. First, we provide a brief overview of existing research on consensus. Then, we present our experimental design and describe our various treatment conditions. We next derive a number of testable hypotheses and explain the logic behind them. We then present the results of our experiments. We conclude with a discussion of the implications that our results have for both theoretical and empirical studies of consensus. 


\section{Existing Research on Consensus}

The necessity or desirability of consensus in legal and political settings has made it a frequent topic of empirical and theoretical investigation. For example, in many jury settings in the United States, consensus among jurors is a necessary condition for a conviction, and the fact that convictions occur tell us that consensus is achievable among jurors (Diamond et al. 2006; Schwartz \& Schwartz 1992). The standard account in the legal literature emphasizes that jury unanimity in criminal cases makes society more comfortable with public participation in matters that implicate individual rights and justice considerations (Abramson 1994). The more consensus that is required, the more likely, so the normative literature on jury decision making insists, that real criminals will be convicted and the innocent will go free (Kalven \& Zeisel 1966). Moreover, consensus requirements (along with particular rules of evidence in legal proceedings) improve the social acceptability of jury decisions (Nesson 1985). Given that the jury is, for appropriate reasons, truly a decision-making "black box," the requirement that the final verdict be unanimous—or, in the case of civil cases, broadly consensual-increases the likelihood that the public will accept the verdict as an expression of society's judgment. "One attraction of unanimity," write Diamond et al., "is that it reflects confidence about the correctness of a decision and the quality of the decision making process" (Diamond et al. 2006:226).

The importance of consensus in legal environments is not limited to jury settings. Coglianese (1997:1256) notes that "federal agencies have begun to employ the consensusbased process known as negotiated rulemaking." In the face of significant critiques of the adversarial quality of modern administrative rule making (see Kagan 2001), "reg-neg" has emerged as a mechanism for reaching valued consensus in regulatory decision making. The premise of reg-neg is that consensual rule making is superior to command and control as a means of reaching sensible regulatory decisions (Harter 1982). It is superior insofar as all interested parties can and will participate in the processes of expert analysis and consideration of tradeoffs. Parties with a stake in the final outcomes can be expected to be better decisionmakers than either legislatures acting in the shadow of interest group politics or so-called administrative experts who bring to bear their own experiences and interests to resolving regulatory disputes and implementing public policy. ${ }^{1}$ Similarly, administrative agencies have attempted to use electronic rule making to encourage greater participation by the public and to move "participants from individual opinion to group choices and plans of action" (Beierle 2003).

Consensus may also be useful in many political settings. For instance, the Consent Calendar in the U.S. House and unanimous consent agreements in the U.S. Senate create the conditions by which much legislation is moved through the process (Bach \& Smith 1988). The committee system can also facilitate consensus either within or across political

\footnotetext{
${ }^{1}$ On the measured value of regulatory negotiation in modern regulation administration, compare Coglianese (1997), " $[\mathrm{n}]$ egotiated rulemaking has long lacked systematic evidence showing that it yields superior results over conventional rulemaking" with Kerwin (1994), "[n] egotiated rulemaking is now a mature concept with a considerable, and largely positive, track record in the development of rules."
} 
party lines (Weingast \& Marshall 1988; Shepsle \& Weingast 1981; Cox \& McCubbins 2005). Delegation to party leaders also helps political parties solve coordination and cooperation problems, which results in largely consensual decision making (Sinclair 2002). Further, particular government institutions (such as proportional representation, strong bicameralism, and executive power sharing) can increase the likelihood of consensual policy making (Lijphart 1999).

In all these settings, the exact process by which consensus occurs is ambiguous, but communication between individuals is central to the development of consensus. DeGroot (1974) develops the canonical model of how iterated communication can help a group of individuals (such as a committee, jury, or group of experts) to reach a consensus about the state of the world or the correct solution to a problem. The essence of the model is the following.

1. Individuals have their own subjective probability distribution about the correct answer to a problem (e.g., jurors have their own beliefs about a defendant's guilt or innocence).

2. Individuals can communicate information regarding their belief about the correct answer (e.g., jurors can discuss their beliefs about guilt or innocence).

3. Individuals observe others' beliefs and then revise their beliefs based on what others believe (e.g., jurors change their beliefs based on what others in the jury believe).

DeGroot shows that if this process of belief statement and revision is allowed to occur infinitely, groups may achieve a consensus in beliefs regardless of the initial distribution of subjective probabilities. The model developed by DeGroot does not specify how individuals must weight others' opinions for consensus to occur, but Berger (1981) shows that consensus requires that individuals do not ignore those who know the correct answer. To put it another way, if individuals only listen to those who do not know the correct answer, the group will not achieve consensus.

The model outlined by DeGroot and the empirical scholarship discussed all make a number of assumptions. Because of their relevance in legal and political settings, these assumptions are the focus of our experiments. In particular, we focus on the assumption that communication among group members is costless. Indeed, in nearly all legal, political, and social settings, sending information and listening to other group members requires time, energy, and attention that could be spent doing other things. Once the costs associated with communicating are taken into account, we show that even when group members have completely aligned interests, consensus is far from trivial to achieve. Specifically, we demonstrate that even small costs to communicate reduce the likelihood that groups reach a consensus by making group members less willing to send information and listen to one another about the correct solutions to various problems. We also show that increasing the difficulty of the problem reduces the likelihood that groups achieve a consensus. By incorporating communication costs and problem difficulty, our study extends existing research on consensus and reveals two factors that hinder a group's ability to reach a consensus, even when all group members have a common interest in reaching the correct solution to a problem. 


\section{An Experimental Test of Consensus}

\section{A. Overview of Experiment}

Although consensus often occurs in the real world, it is difficult to isolate the factors that facilitate or hinder consensus in observational settings. Therefore, we use an experiment to analyze different factors that may affect a group's ability to reach a consensus about the correct solution to a problem. Of course, designing an experiment requires us to simplify the world so that it can be examined in a laboratory setting. Nonetheless, we incorporate the following aspects of real-world contexts in our experiments: ${ }^{2}$ multiple decisionmakers; an uncertain state of the world; the opportunity to send information about one's beliefs about the state of the world to others; the opportunity to receive information about others' beliefs; and an incentive for individuals and groups to reach consensus about the state of the world.

Specifically, we include multiple subjects in each experiment, which creates a smallgroup environment that is similar to real-world legal and political settings. In the experiment, subjects are faced with the task of deciding the correct answers to math problems about which they are uncertain (i.e., subjects do not necessarily know the correct answers to the math problems). ${ }^{3}$ These math problems are drawn from an SAT math test, and we provide two possible answers for each question (Answer A or Answer B), one of which is correct and the other of which is incorrect. As is true of real-world problems, the problems used in our experiments vary in their level of difficulty. Specifically, we measure problem difficulty by having a separate group of subjects solve the problems on their own prior to conducting these experiments. ${ }^{4}$ We use the percentage of these subjects who answered a problem correctly as a measure of the relative ease or difficulty of each problem. That is, problems with smaller percentages of correct answers are more difficult than problems with larger percentages of correct answers.

In the experiments, subjects earn $\$ 1$ for every problem they answer correctly, lose $\$ 1$ for every problem they answer incorrectly, and neither earn nor lose money if they do not

\footnotetext{
${ }^{2}$ These features are also present in DeGroot's (1974) model of iterative consensus, which itself is essentially a formalized version of the Delphi experimental model, according to Gilardoni and Clayton (1993). The Delphi model was developed by RAND Corporation in the 1940s, 1950s, and 1960s as a mechanism to elicit experts' opinions about particular topics. Since its creation, the Delphi model has been the subject of numerous academic experiments and has been implemented widely for practical policy-making purposes. In fact, the Delphi method is still widely used in business, government, and nonprofit organizations. For example, Teleos Company uses the Delphi method to identify the winner of the Most Admired Knowledge Enterprises awards and similar awards for cities across the world. Sackman (1974) provides a comprehensive review of research on the Delphi method. Although experiments on group decision making have been done before, we make a significant addition by explicitly incorporating costs to send and/or receive information.
}

\footnotetext{
${ }^{3}$ We use math problems because we can easily observe whether or not subjects reach a consensus about the correct answer. For a more complete discussion of how and why math problems are analogous to real-world problems, see Boudreau (2009)
}

${ }^{4}$ Like subjects in our experiments, this separate group of subjects also earned money for answering problems correctly, lost money for answering problems incorrectly, and earned nothing if they left a problem blank. 
answer the problem. ${ }^{5}$ Consensus is defined as whether enough subjects in the group answer a math problem correctly to exceed a commonly known threshold (unanimity in the reported experiments). If the group achieves a consensus about the correct answer to a problem, then each subject earns an additional $\$ 10$. Thus, the maximum amount of money each subject can earn on a particular problem is $\$ 11$. This payment structure creates common interests among all subjects in reaching a consensus about the correct answer to the problem.

A common mechanism that creates consensus in real-world settings is the exchange of information among individuals. Therefore, during our experiments subjects have the opportunity to exchange information with one another. In the experiment, we divide this communication process into two steps-sending information to other subjects and receiving information from other subjects. Specifically, for each math problem in the experiment, subjects are first given 60 seconds to determine whether they know the correct answer and to consider whether they might like to send and/or receive information about it. Following the initial 60-second period, each subject chooses whether he or she would like to send information (in the form of "Answer A" or "Answer B") to the other subjects about what he or she believes is the correct answer. Simultaneously, each subject also chooses whether he or she would like to receive information from the other subjects about what they believe is the correct answer. ${ }^{6}$ Both decisions are completely anonymous in that each subject does not know which (or how many) other subjects chose to send or receive information. ${ }^{7}$

After subjects decide whether to send and/or receive information, the experimenters aggregate the number of subjects (if any) who chose to send information, and among those the number of subjects who believe that $\mathrm{A}$ is the correct answer and the number of subjects who believe that $\mathrm{B}$ is the correct answer. The experimenters then provide this information to those subjects who chose to receive this information. Following this communication process, all subjects have an additional 60 seconds to decide whether they would like to answer the problem and, if so, whether to choose A or B as their final answer. It is the answer that subjects choose here that determines whether they, individually, earn or lose $\$ 1$ and whether they, as a group, earn an additional $\$ 10$ for reaching a consensus about the

\footnotetext{
${ }^{5}$ Subjects were college undergraduates at a large university in southern California.
}

${ }^{6}$ The rationale for requiring simultaneous decision making is that in real-world settings, we must decide to attend to information before we know what others have said (see Lupia \& McCubbins 1998:ch. 2). Because subjects' decisions to send and/or receive information happen at the same time, subjects cannot condition their choice to receive information on whether or not someone else chose to provide information. If the decisions to send and receive information were sequential, then subjects might believe that if they send information it will encourage others to receive information. However, the simultaneity of decision making means that subjects cannot learn whether someone has sent information until after they choose to receive information. Thus, potential senders of information will not believe their decision will influence the behavior of potential receivers of information.

${ }^{7}$ We purposely do not provide subjects with information about the characteristics of those who suggested answers because we do not want to affect subjects' assessments of each other in ways that we cannot understand. For similar reasons, subjects sit behind partitions so that they cannot see, hear, or directly talk to one another. 
correct solution. At the completion of this process, subjects receive a new problem, perhaps under a different treatment condition. No feedback is given to subjects about their (or the group's $)^{8}$ performance on the previous problem, and all the procedures and payoffs that are used are common knowledge.

\section{B. Treatment Conditions}

We used the basic design described above in all our experiments. We then modified elements of this basic design to test how costs of communication affect subjects' ability to reach a consensus. To test how changes in the costs of communication affect subjects' decisions and their ability to reach a consensus, we employ the following treatment conditions in our experiments.

1. Subjects must pay a cost to send information, but not to receive information.

2. Subjects must pay a cost to receive information, but not to send information.

3. Subjects must pay a cost to send and receive information.

We also vary the specific cost of sending and/or receiving information to test how changes in the size of the cost affect subjects' decisions. Specifically, depending on the treatment condition, we impose a $\$ 0.10, \$ 0.25, \$ 1$, or $\$ 2$ cost to send and/or receive information. In all three of the treatment conditions listed above, we impose a $\$ 2$ cost to send and/or receive information. The other, smaller costs (i.e., $\$ 0.10, \$ 0.25$, and $\$ 1$ ) are only used in the treatment condition in which subjects must pay a cost to send and receive information. Further, in the treatment condition where there is a cost to send and receive information, the cost of sending information is the same as the cost of receiving information (i.e., if there is a $\$ 0.10$ cost to send information, then there is a $\$ 0.10$ cost to receive information). This creates a total of six treatment conditions. Our control condition is the costless communication process that we described above, which provides a baseline for how well subjects and groups make decisions when they can send and receive information without paying a cost.

Within each session of the experiment, we include the control condition, as well as several treatment conditions. For example, in a given experiment, a single group of subjects first solves four math problems without paying a cost to send and receive information. This same group of subjects might then solve four problems with a $\$ 2$ cost to send information and then another four problems with a $\$ 2$ cost to send and receive information. This design gives us substantial inferential power because we are able to make comparisons within subjects and groups (i.e., comparing the performance of a single group of subjects across several treatment conditions), as well as between subjects and groups (i.e., comparing the performance of different groups of subjects exposed to different treatment conditions).

${ }^{8}$ We do this to reduce (if not eliminate) the opportunity for subjects to learn about others in the group. Indeed, we cannot control what subjects might learn and how this might affect their behavior on subsequent problems. 


\section{Predictions About Individual and Group Behavior}

In this section, we outline the predictions for our experiment. ${ }^{9}$ We focus first on how changes in the costs of communication and the difficulty of a problem affect a group's ability to reach a consensus. We then turn to predictions regarding the mechanism by which consensus occurs-communication-and consider how the costs associated with communicating affect individuals' decisions to send and/or receive information. The key aspect of our predictions involves the strategic nature of communication and the way that the costs of communication affect the game between subjects.

\section{A. Consensus Predictions}

Free Communication-Consensus Prediction: When it is costless to send and receive information, consensus is the most likely to occur, all else equal.

Costly Communication-Consensus Prediction: When it is costly to send and/or receive information, consensus is less likely to occur than when communication is free, all else equal.

These predictions follow from the role of communication in the creation of consensus. If communication increases the probability of a group achieving a consensus and if costs (for sending and/or receiving information) reduce communication, then costs for communication will also reduce the probability of a group achieving a consensus. We explicitly describe how costs affect communication and analyze the effect of costs on communication in the next section.

Difficulty-Consensus Prediction: Consensus will be less likely on more difficult problems, all else equal.

As a problem becomes more difficult, it is less likely that subjects will know the correct answer. This reduces the probability that all subjects in the group will be able to answer the problem correctly on their own (i.e., without communication). It also makes communication about the correct answer less likely and less effective, as the probability that subjects will be able to recommend the correct answer to others also declines as the difficulty of the problem increases.

\section{B. Communication Predictions}

Our primary focus in this article is on how communication costs and problem difficulty affect a group's ability to reach a consensus about the correct solution to a problem. In both cases, we expect that groups will be less likely to reach a consensus because costs and difficult problems impede communication. Therefore, we now present predictions about how costs and problem difficulty influence communication.

Free Communication Prediction: When it is costless to send and receive information, subjects will be most likely to send and receive information, all else equal. 
When communication is costless, we expect that subjects will communicate with one another about the correct answer to a problem. Specifically, when it is costless to receive information about what other subjects believe is the correct answer, subjects should choose to receive such information. The reason for this is that all subjects in the group have a common interest in reaching a consensus about the correct answer to a problem. Thus, subjects need not worry about other subjects trying to deceive them (Crawford \& Sobel 1982). Indeed, only those subjects who know the correct answer should send information to others, and they should truthfully reveal what they know. Further, if subjects who know the correct answer to a problem believe that other subjects will choose to receive information (which they should believe, given that it is free to receive information), then they have an incentive to send information about what they know. This free exchange of information should facilitate a group's ability to reach consensus.

Costly Sending Prediction: When it is costly to send information, fewer subjects will choose to send information. However, the cost of sending information will not affect subjects' propensity to receive information.

The logic behind this prediction is straightforward. Specifically, although the private benefit of sending information has not changed, the cost of doing so has. Therefore, fewer subjects should be willing to pay the cost to send information to others. However, because receiving information is free, subjects should still choose to receive information.

Costly Listening Prediction: When it is costly to receive information, fewer subjects will receive information, and therefore, fewer subjects will send information.

We implement two treatment conditions in which it is costly to receive information-a costly receiving condition and a costly sending and receiving condition. The prediction applies to both conditions. In experiments where it is costly to receive information, subjects have two choices. First, they may choose to pay the cost to receive information about what other subjects believe is the correct answer. If subjects choose to pay this cost, then they have a dominant strategy to answer the problem and choose the answer indicated by the information, as only knowledgeable subjects should choose to send information and their dominant strategy is to send the correct answer. Second, subjects may choose not to pay the cost associated with receiving information and thus not receive the information about what others recommend as the correct answer. ${ }^{10}$ If subjects choose not to pay the cost to receive information, they then must choose whether to answer the problem on their own (according to their prior beliefs regarding the correct answer) or not to answer the problem.

The probability that a particular subject will be pivotal (and will thus determine whether the group reaches a consensus by his or her decision to acquire information) goes to zero as the size of the group increases. Indeed, if a subject is in a group of four and the

\footnotetext{
${ }^{10}$ If we model only the actions of the receivers, the game reduces to a multiperson dilemma game (Schelling 1978). The key simplification to multiperson dilemma games is the assumption that each player has a purely binary choice, and that the interaction is impersonal in the sense that each player's payoff depends only on the number of others making one choice or the other, and not on the identities of these choosers.
} 
subject believes that everyone else has a 50-50 chance of answering the problem correctly, then only once in eight trials will the subject actually be pivotal. Therefore, subjects should not believe they are pivotal in equilibrium.

If being pivotal is extremely unlikely, then subjects must decide if the private benefit of receiving information exceeds the cost of the information. This decision involves a subject's probability of answering correctly, the probability of someone sending correct information, and the cost of the information. Each subject will have his or her own subjective probability of answering correctly that is related to the difficulty of the problem. In our model and experiments, all subjects already have common interests, so increases in the cost of information do not increase the probability of someone sending correct information. Therefore, as the cost of information increases, subjects will be less likely to receive information because the price of information rises but its expected value does not. As the number of subjects who are likely to receive information declines, subjects should be less likely to send information because they should know that no one will be listening and therefore have no reason to send information. The prediction that speakers will choose not to send information if they are indifferent between sending information and not sending information is based on Lupia and McCubbins (1998:chs. 2, 3), where they defend on cognitive grounds the assumption that if speakers do not believe anyone will listen to their statements, they do not bother to send information in the first place. ${ }^{11}$

Difficulty-Communication Prediction: As the problems become more difficult, subjects will be less likely to send information, all else equal.

The logic behind this prediction is straightforward. When problems are more difficult, fewer subjects will know the correct answer to the problem. This reduces the number of subjects who will be able to recommend the correct answer to the other subjects in the group.

\section{Results from Consensus Experiments}

In this section, we present the results of our one-shot communication experiments. ${ }^{12}$ The experiments used both within-subjects and between-groups designs. In every experiment, we exposed subjects to multiple treatment conditions, but due to time and attention constraints, we could not expose subjects to all six treatment conditions in a single

\footnotetext{
${ }^{11}$ In the context of our experiments, the cognitive reason for not sending information may be that subjects must determine the correct answer before sending information, and if no one is listening, then it is not worth the effort.

${ }^{12}$ Our decision to focus on only one round of communication is supported by Boudreau and McCubbins (2008). They show that when it is costless for subjects to go back and forth exchanging reasons for why particular choices may be correct, the reasons quickly degenerate into cheap talk or babbling. That is, although subjects use all their opportunities to exchange reasons, the reasons that subjects send in the later trials have little or nothing to do with the task at hand. As the cost to send reasons increases from $\$ 0$ to $\$ 2$, there is a reduction in the number of times that subjects choose to exchange reasons.
} 
experimental session. Therefore, our results also make comparisons between different groups of subjects.

For most of our analyses we use a multilevel logit model with a varying intercept parameter (Gelman \& Hill 2007). The varying intercept is based on the experimental group because there may be differences between the groups that we cannot directly observe but that affect behavior. That said, we do not simply rely on the random-intercept model to adjust for differences between groups. ${ }^{13}$ We also measure individual and group-level attributes that may affect behavior during the experiment. At the individual level, we know a subject's SAT math score and GPA, both of which may affect subjects' decisions to send and receive information. We also use this data to compute each group's average SAT math score and GPA. We also include covariates to account for the size of the group and the difficulty of the math problems.

We predicted that consensus would be most likely when communication is costless and that imposing costs to send and/or receive information would decrease the likelihood of consensus. In Table 1 we present the results of a multilevel logit model that examines the likelihood of consensus in different treatment conditions. The unit of analysis in this regression is whether a given group achieves consensus- that is: Do all members of the group answer a given problem correctly? This unit of analysis means that we have multiple observations for each group. The control condition in this regression (the omitted category) is the experimental condition in which communication is costless. We use the condition in which subjects could communicate freely with one another as the control condition because that allows the most direct test of our prediction that costs to send and/or receive information reduce consensus relative to free communication. We include dummy variables that represent our various treatment conditions (i.e., dummy variables for costs to send, costs to receive, and costs to send and receive), as well as variables that reflect the size of the cost to communicate, the average SAT math score and GPA for each group, the number of subjects in each group, and the difficulty of the math problems.

The results in Table 1 are quite striking. As expected, groups are significantly more likely to reach a consensus when communication is free, relative to when subjects must pay a cost to communicate. In particular, if it costly to receive information or costly to send and receive information, there is a significantly lower probability of consensus. The particular size of the cost has no direct effect, which suggests that even small costs impede consensus. Consistent with our predictions, we also find that easier problems significantly increase the likelihood of consensus, while more difficult problems decrease it. We also see that as groups increase in size, consensus is less likely, which reflects the greater difficulty of everyone answering a problem correctly as the size of the group increases. Taken together,

\footnotetext{
${ }^{13}$ The advantage of randomly assigning subjects to different treatment conditions is that in expectation the treatment is orthogonal to relevant covariates. The treatments we are most interested in are the treatment conditions described above (i.e., manipulating the costs associated with speaking and/or listening), as well as the different size costs to communicate. However, the difficulty of the math problems also affects the probability of communicating and reaching a consensus. We attempt to balance problem difficulty and our various treatment conditions across all our groups to ensure that groups do not receive a combination of problem difficulty and treatment condition that make communication or consensus particularly (un) likely. However, given the number of possible combinations, it is unlikely that we have achieved complete balance and the varying intercept model helps account for that problem.
} 
Table 1: Costs to Communicate Reduce Consensus and Easier Problems Increase Consensus

\begin{tabular}{lc}
\hline & $D V=$ Consensus \\
\hline Pay to send information, but not to receive information & $-0.56(0.76)$ \\
Pay to receive information, but not to send information & $-3.16(0.93)^{* *}$ \\
Pay to send and receive information & $-3.03(0.91)^{* *}$ \\
Cost to communicate & $-0.31(0.63)$ \\
Average SAT math score & $0.04(0.01)^{* *}$ \\
Average GPA & $-0.11(1.92)$ \\
Ease of problem & $0.09(0.02)^{* *}$ \\
Number of subjects & $-0.32(0.12)^{* *}$ \\
Constant & $-28.9(10.8)^{* *}$ \\
$N$ & 246 \\
Number of groups & 23 \\
Random Effect Parameter & $0.89(0.56)$ \\
Group effect & 0.14 \\
LR test vs. standard logistic regression (chi2) & 23 \\
\hline Notes: *Significant at 0.05 level, **significant at 0.01 level, two-tailed test. Regression estimated as a multilevel logit \\
model with a varying intercept for each experimental group. Dependent variable is whether all members of a group \\
answered a problem correctly. Omitted condition represents free communication, so the estimates for the three other \\
treatment variables are relative to the free communication condition. A negative coefficient indicates that a particular \\
treatment condition makes consensus less likely compared to the control condition (free communication). A positive \\
coefficient indicates that changes in that variable are associated with a greater probability of consensus.
\end{tabular}

these results show that costly communication and difficult problems are significant barriers to consensus.

We now investigate the effect of costs and difficulty on communication, which is the primary mechanism that influences a group's ability to reach a consensus. In our analysis, we break communication into its component parts—sending and receiving information. An observation in this analysis is a given subject's decision on a specific problem. Therefore, for each subject we have as many observations as problems. For instance, if a subject took part in 16 problems, we have 16 observations for that subject. Given that there are eight subjects in each of the experiments included in this analysis, we would have a total of 128 (8 multiplied by 16) observations from this particular experiment. ${ }^{14}$ These observations are divided among a number of different treatment conditions, which provides us with within-subject observations. We also rely on between-subject observations to make comparisons between treatment conditions that we could not fit in a particular session of the experiment.

We focus first on how costs affect subjects' decisions to receive information. Although we typically use regressions to analyze our data, subjects' behavior is so close to our theoretical predictions that it is not possible to perform a regression-based analysis here. As

\footnotetext{
${ }^{14}$ In our analysis of consensus, we pooled together experiments with different size groups to increase our overall sample size because for each question we only observe a single outcome (consensus or not). In our analysis of sending and receiving information, we restrict ourselves to analyzing behavior in groups of eight subjects because we have sufficient observations to do so and this restriction holds constant group size.
} 
Table 2: Subjects Receive Information Less Often When it is Costly to Do So

\begin{tabular}{|c|c|c|c|c|}
\hline & $\begin{array}{c}\text { Free } \\
\text { Communication }\end{array}$ & $\begin{array}{c}\text { Cost to Send, } \\
\text { No Cost to Receive }\end{array}$ & $\begin{array}{l}\text { Cost to Receive, } \\
\text { No Cost to Send }\end{array}$ & $\begin{array}{l}\text { Cost to Send } \\
\text { and Receive }\end{array}$ \\
\hline $\begin{array}{l}\text { Proportion of observations } \\
\text { where a subject received }\end{array}$ & 0.98 & 1 & 0.07 & 0.12 \\
\hline $\begin{array}{l}\text { information ( } S D \text {, number } \\
\text { of observations) }\end{array}$ & $(0.01)$ & $(0)$ & $(0.02)^{* * *}$ & $(0.03)^{* * *}$ \\
\hline$N$ & 128 & 48 & 96 & 144 \\
\hline
\end{tabular}

Notes: **Significantly different than free communication condition at 0.01 level, two-tailed difference-in-proportion test, when compared to the free communication condition. The dependent variable is a subject's decision to receive information for a given question. An observation is a subject-question, so if we have eight subjects and four questions that would generate 32 observations. All the costly conditions included a $\$ 2$ cost, with eight subjects in the group.

Table 3: Sending Information is Reduced by Both Costly Sending and Receiving

\begin{tabular}{lcccc}
\hline & $\begin{array}{c}\text { Free } \\
\text { Communication }\end{array}$ & $\begin{array}{c}\text { Cost to Send, } \\
\text { No Cost to Receive }\end{array}$ & $\begin{array}{c}\text { Cost to Receive, } \\
\text { No Cost to Send }\end{array}$ & $\begin{array}{c}\text { Cost to Send } \\
\text { and Receive }\end{array}$ \\
\hline $\begin{array}{l}\text { Proportion of observations } \\
\text { where a subject sent } \\
\text { information }(S D)\end{array}$ & 0.48 & 0.16 & 0.34 & 0.04 \\
$N$ & $(0.04)$ & $(0.05)^{* *}$ & $(0.05)^{*}$ & $(0.01)^{* * *}$ \\
\hline
\end{tabular}

Notes: *Significantly different at 0.05 level, **significantly different at 0.01 level, two-tailed difference-in-proportion test, when compared to the free communication condition. The dependent variable is a subject's decision to send information. An observation is a subject-question, so if we have eight subjects and four questions that would generate 32 observations. All the costly conditions evaluated at $\$ 2$ cost, with eight subjects in the group.

shown in Table 2, nearly every subject chooses to receive information when communication is costless, as well as when it is costly to send information, but free to receive it. This is exactly as we predicted. We can also use a difference-in-proportions test to determine whether our various treatment conditions are significantly different from one another. Not surprisingly, the results in Table 3 show that when it is costly to receive information, subjects are significantly less likely to receive it than when communication is costless.

We next analyze subjects' decisions to send information about what they believe is the correct answer to a given problem. Again, we expect that when communication is costless, subjects will be most likely to send information to the other subjects. We also predict that when receiving information is costly (even if sending information is free), there will be a significant reduction in subjects' propensity to send information because possible senders realize that other subjects will not pay to listen. In Table 3 we present the proportion of subjects in each treatment condition that chose to send information and compare this to the proportion of subjects that chose to send information when communication was free. Costly communication (i.e., costly sending, costly receiving, or both) clearly reduces subjects' willingness to send information.

We also use a regression to analyze subjects' decisions to send information because it allows us to account for a variety of individual and group factors. Specifically, in Table 4 we present the results of a multilevel logit model with a random intercept for each experimen- 
Table 4: Costs to Communicate and Problem Difficulty Reduce the Probability that Subjects Send Information

\begin{tabular}{lccc}
\hline & $\begin{array}{c}\text { Free vs. Costly } \\
\text { Sending }\end{array}$ & $\begin{array}{c}\text { Free vs. Costly } \\
\text { Receiving }\end{array}$ & $\begin{array}{c}\text { Free vs. Costly Sending } \\
\text { and Receiving }\end{array}$ \\
\hline Pay to send information, receive for free & $-1.25(1.00)$ & - & - \\
Pay to receive information, send for free & - & $-0.99(0.58) *$ & N/A \\
Pay to send and receive condition & - & - & $-1.96(0.49)^{* *}$ \\
Individual SAT math score & $0.006(0.004)$ & $-0.0004(0.004)$ & $0.008(0.003)^{* *}$ \\
GPA & $2.43(1.54)$ & $-0.63(0.83)$ & $-0.42(0.49)$ \\
Group average SAT math score & $-0.05(0.05)$ & $0.01(0.02)$ & $-0.01(0.02)$ \\
Ease of problem & $0.06(0.02) * *$ & $0.05(0.01)^{* *}$ & $0.03(0.008)^{* *}$ \\
Constant & $18.9(30.6)$ & $-9.39(11.97)$ & $1.73(14.9)$ \\
$N$ & 82 & 100 & 376 \\
Number of groups & 4 & 4 & 8 \\
Random Effect Parameter & & & $0.63(0.32)$ \\
Experimental group & $0.62(0.69)$ & 0 & $3.28^{*}$ \\
LR test vs. standard logistic regression (chi2) & 0.29 & 0 & \\
\hline
\end{tabular}

Notes: *Significant at 0.05 level, **significant at 0.01 level, one-tailed test. The excluded category is the experimental condition with free communication. All experimental groups contained eight subjects. Regression estimated as a multilevel logit model with a varying intercept for each experimental group. A negative coefficient, for instance, on the variable "Pay to receive, send for free" indicates that increases in the variable makes sending information less likely. A positive coefficient, for instance, on "Ease of problem" indicates that increases in that variable makes sending information more likely.

tal group. ${ }^{15}$ The first column of Table 4 compares the condition in which communication is free to the treatment condition in which it is costly to send information. The second column compares free communication to the treatment condition in which it is costly to receive information. The third column compares free communication to the treatment condition in which it is costly to send and receive information. We expect each of these treatment conditions to have a negative effect on subjects' decisions to send information, relative to when it is completely free to communicate.

Turning first to the effect of the treatment condition in which it is costly to send information, we find that although the sign on the variable for this treatment condition is in the expected direction (negative), it does not reach standard levels of significance. In Column 2 of Table 4 we investigate the effect of the treatment condition in which it is costly to receive information. As predicted, we find that this treatment condition is associated with a significant decrease in the likelihood of sending information. This is an important result because it indicates that even when it is costless to send information, if individuals must pay a cost to listen, there is a significant negative effect on subjects' propensity to send information. Finally, we turn to the treatment condition in which it is costly to send and receive information. This treatment condition also has a significant, negative effect on subjects' propensity to send information to others, which is consistent with our predictions. Taken

\footnotetext{
${ }^{15}$ The regressions in Table 4 are limited to the subset of data where we have similar levels of problem difficulty in the different conditions. If we do not limit our analysis to areas in which there is overlap of problem difficulty between conditions, we cannot disentangle problem difficulty from the treatment/control condition.
} 
Table 5: Even Small Costs Reduce Subjects' Willingness to Send Information

\begin{tabular}{lccccc}
\hline & Free Communication & $\$ 0.10$ & $\$ 0.25$ & $\$ 1$ & $\$ 2$ \\
\hline Proportion of times subjects & 0.48 & 0.07 & 0.16 & 0.05 & 0.04 \\
$\quad$ SENT information $(S D)$ & $(0.04)$ & $(0.02)$ & $(0.06)$ & $(0.02)$ & $(0.02)$ \\
$N$ & 128 & 96 & 48 & 96 & 144 \\
\hline
\end{tabular}

Notes: *All differences are significant at the 0.01 level when compared to the free communication condition. The dependent variable is individuals' decisions to send information for a given question. All observations were from groups with eight subjects and costs were required to send and receive information.

Table 6: Even Small Costs Reduce Subjects' Willingness to Receive Information

\begin{tabular}{lccccc}
\hline & Free Communication & $\$ 0.10$ & $\$ 0.25$ & $\$ 1$ & $\$ 2$ \\
\hline $\begin{array}{l}\text { Proportion of time subjects } \\
\text { RECEIVED information }\end{array} \quad 0.98$ & 0.36 & 0.56 & 0.08 & 0.12 \\
$\quad(S D)$ & $(0.01)$ & $(0.05)$ & $(0.07)$ & $(0.03)$ & $(0.03)$ \\
$N$ & 128 & 96 & 48 & 96 & 144 \\
\hline
\end{tabular}

Notes: **All differences are significant at the 0.01 level when compared to the free communication condition. The dependent variable is individuals' decisions to send information for a given question. All observations were from groups with eight subjects and costs were required to send and receive information.

together, these results show quite clearly that communication costs reduce the probability of subjects sending information to one another. Not surprisingly, we also find that subjects are more likely to send information when the math problem is easier (and, conversely, are less likely to send information when the math problem is more difficult) in each of these treatment conditions.

In the treatment conditions where it is costly to send and receive information, we also examine the effects of different size costs: namely, a $\$ 0.10, \$ 0.25, \$ 1$, and $\$ 2$ cost to send and receive information. In Table 5 we display subjects' decisions to send information by the particular cost. It is readily apparent that even a minimal cost of $\$ 0.10$ eliminates subjects' willingness to send information to others. In Table 6 we display subjects' decisions to receive information based on the cost of doing so. Again, we see that even a very minimal cost causes a profound decrease in the number of subjects who choose to receive information. Given this, it makes perfect sense that few subjects choose to send information at low costs because few people are paying attention. That even small costs eliminate subjects' willingness to send and receive information is remarkable because, in all these treatment conditions, subjects stand to gain $\$ 10$ if they reach a consensus.

Taken together, our results yield a number of robust findings. First, communication costs cause a marked reduction in the probability that a group achieves a consensus. ${ }^{16}$

\footnotetext{
${ }^{16}$ The results described above demonstrate that communication costs and problem difficulty significantly reduce subjects' willingness to send information and listen to one another, as well as their ability to reach a consensus about the correct solutions to various problems. We also considered the effect of communication costs when we allowed
} 
Second, we show that costs to communicate significantly reduce subjects' willingness to send information and listen to one another, which impedes consensus. Interestingly, costs to receive information both reduce the probability that subjects receive information and that subjects send information. After all, what is the purpose of sending information if no one is listening? Third, groups are less likely to reach a consensus when the problems are more difficult. The apparent cause of this decreased ability to reach a consensus is the decrease in subjects' willingness or ability to communicate about the solutions to more difficult problems. Unfortunately, these are exactly the types of problems where communication is most needed in real-world settings.

\section{Conclusion}

The ability of groups to reach a consensus is a core concern in legal, political, and social settings. Empirical scholarship places a premium on the role of communication and learning from others in the development of consensus. Formal models of consensus also consider how individuals can communicate with one another to reach the same beliefs or take the same action as the rest of the group. However, most formal models ignore the costs associated with communication, and thereby fail to account for strategic elements of communication that affect a group's ability to reach a consensus.

In this article, we test how communication costs and problem difficulty affect groups' ability to achieve consensus. We also assess how the costs of communicating affect subjects' willingness to signal and listen to one another. We find that when communication is costless, groups are able to achieve consensus, primarily because they are willing to communicate with one another. Once communication becomes costly or once the problems become more difficult, there is a significant negative effect on groups' ability to achieve consensus and on subjects' willingness to communicate. Importantly, our results suggest that even a small cost (relative to the size of the benefit of reaching a consensus) reduces subjects' willingness to communicate with one another. In addition, costs to receive information reduce subjects' willingness to receive information, and also subjects' willingness to signal information. Together, these results indicate that people must perceive

repeated communication. We only conducted a few of these experiments, but it quickly became clear that the results were consistent with our predictions (full results are available on the authors' website). The most important result is that our primary predictions about the effect of costs are borne out for both sending and receiving behavior-as the cost to communicate increases, there is markedly less communication among subjects.

When we examine subjects' ability to answer problems correctly, our findings are also similar to those from the one-shot communication experiments. Most importantly, as the costs of communicating increase, fewer subjects answer the problems correctly. That said, we do find that repetition in the number of rounds leads to a greater proportion of subjects answering problems correctly. It also appears that repetition can increase the likelihood of consensus. However, two points are worth emphasizing: consensus never happens at costs greater than $\$ 0.25$ to send and receive information and consensus never occurs more than half the time. These results should be interpreted with caution because they only involve two or three groups of eight subjects interacting for three or four problems per treatment condition. However, in all these experiments, we find that when subjects must pay a cost to communicate, there is a considerable decline in sending, receiving, and answering problems correctly, even over multiple rounds of communication. 
communication to be very inexpensive for them to choose to signal and listen to others and that people may not be willing to communicate when problems are difficult.

Legal and political institutions can facilitate consensus by making communication cheaper and problems easier. Our theory and results demonstrate that it is the cost of receiving information that is the primary hindrance to communication and consensus. One way that institutions can reduce the costs of receiving information is by making information easier to understand. For example, allowing jurors to take notes during trials is one institution that might make it easier for jurors to comprehend and remember complex testimony, thereby reducing the cost-benefit ratio associated with listening. Institutions might also influence the opportunity costs people pay if they choose to attend to information. For example, legal and political institutions that allow individuals to verify the information they receive from other members of the group might reduce the perceived costs associated with listening. Institutions can also encourage communication by ensuring that there are people in the group who are knowledgeable about the problem at hand. Knowing that individuals in the group are knowledgeable, others in the group might be more inclined to listen. All these approaches can make problems easier and may encourage communication and consensus. The results of this article suggest that if we want to achieve consensus, we must design our institutions in a way that takes account of the factors that impede consensus.

\section{REFERENCES}

Abramson, Jeffrey B. (1994) We, the Jury: The Jury System and the Ideal of Democracy. New York: Basic Books.

Bach, Stanley, \& Steven S. Smith (1988) Managing Uncertainty in the House of Representatives: Adaptation and Innovation in Special Rules. Washington, DC: Brookings Institution Press.

Beierle, Thomas C. (2003) Discussing the Rules: Electronic Rulemaking and Democratic Delibercation, Discussion Paper 03-22, Resources for the Future.

Berger, Roger L. (1981) "A Necessary and Sufficient Condition for Reaching a Consensus Using DeGroot's Method," 76(374) J. of the American Statistical Association 415.

Boudreau, Cheryl (2009) "Closing the Gap: When Do Cues Eliminate Differences Between Sophisticated and Unsophisticated Citizens?” 71(3) J. of Politics 964.

Boudreau, Cheryl, \& Mathew D. McCubbins (2008) "Nothing But the Truth: Experiments on Adversarial Competition, Expert Testimony, and Decision Making," 5(4) J. of Empirical Legal Studies 751.

Coglianese, Cary (1997) "Assessing Consensus: The Promise and Performance of Negotiated Rulemaking," 46 Duke Law J. 1255.

Cox, Gary W., \& Mathew D. McCubbins (2005) Setting the Agenda: Responsible Party Government in the US House of Representatives. New York: Cambridge Univ. Press.

Crawford, Vincent, \& Joel Sobel (1982) "Strategic Information Transmission," 50 Econometrica 1431.

DeGroot, Morris H. (1974) "Reaching a Consensus," 69(345) J. of the American Statistical Association 118.

Diamond, Shari, Mary R. Rose, \& Beth Murphy (2006) "Revisiting the Unanimity Requirement: The Behavior of the Non-Unanimous Civil Jury," 100 Northwestern Univ. Law Rev. 201.

Gelman, Andrew, \& Jennifer Hill (2007) Data Analysis Using Regression and Multilevel/Hierarchical Models. New York: Cambridge Univ. Press.

Gilardoni, Gustavo L., \& Murray K. Clayton (1993) "On Reaching a Consensus Using Degroot's Iterative Pooling," 2(1) Annals of Statistics 391.

Harter, Philip (1982) "Negotiating Regulations: A Cure for Malaise," 71(15) Georgetown Law J. 1. 
Kagan, Robert (2001) Adversarial Legalism: The American Way of Law. Cambridge: Harvard Univ. Press. Kalven, Harry Jr., \& Hans Zeisel (1966) The American Jury. Chicago, IL: Univ. of Chicago Press.

Kerwin, Cornelius M. (1994) Rulemaking: How Government Agencies Write Law and Make Policy. Washington, DC: CQ Press.

Lijphart, Arend (1999) Patterns of Democracy. New York: Cambridge Univ. Press.

Lupia, Arthur, \& Mathew D. McCubbins (1998) The Democratic Dilemma: Can Citizens Learn What They Need to Know? New York: Cambridge Univ. Press.

McCubbins, Mathew D., \& Daniel Rodriguez (2006) "When Does Deliberating Improve Decision Making?" $15 \mathrm{~J}$. of Contemporary Legal Issues 9.

Nesson, C. (1985) "The Evidence or the Event? On Judicial Proof and the Acceptability of verdicts," 987 Harvard Law Rev. 1357.

Sackman, H. (1974) Delphi Assessment: Expert Opinion, Forecasting, and Group Process, report prepared for U.S. Air Force Project RAND.

Schelling, Thomas (1978) Micromotives and Macrobehavior. New York: Norton Press.

Schwartz, Edward P., \& Warren Schwartz (1992) "Decisionmaking by Juries Under Unanimity and Supermajority Voting Rules," 80 Georgetown Law J. 775.

Shepsle, Kenneth A., \& Barry R. Weingast (1981) "Political Preferences for the Pork Barrel: A Generalization," 25(1) American J. of Political Science 96.

Sinclair, Barbara (2002) Unorthodox Lawmaking. Washington, DC: CQ Press.

Weingast, Barry, \& William J. Marshall (1988) "The Industrial Organization of Congress; or Why Legislatures, Like Firms, Are Not Organized as Markets," 96(1) J. of Political Economy 132. 